\title{
CT-guided ${ }^{125}$ I brachytherapy on pulmonary metastases after resection of colorectal cancer: A report of six cases
}

\author{
SHUYUAN SHI ${ }^{1 *}$, JINGKUI YANG ${ }^{1 *}$ and DAQIANG SUN ${ }^{2}$ \\ ${ }^{1}$ Department of Thoracic Surgery, Second Hospital of Tianjin Medical University, Tianjin 300211; \\ ${ }^{2}$ Department of Thoracic Surgery, Tianjin Chest Hospital, Tianjin 300051, P.R. China
}

Received January 31, 2014; Accepted September 26, 2014

DOI: $10.3892 / \mathrm{ol} .2014 .2649$

\begin{abstract}
Colorectal cancer (CRC) is one of the most common malignancies in the world and distant metastasis is the main cause of cancer-related mortality. Percutaneous computed tomography (CT) guided radioactive ${ }^{125}$ I seed implantation (CTRISI) is a minimally invasive technique used to treat pulmonary metastases in CRC patients. In the present study, following colorectal cancer resection, six patients with pulmonary metastases were treated with computed tomography (CT)-guided percutaneous implantation of radioactive ${ }^{125} \mathrm{I}$ seeds. At six months following seed implantation, CT examination was performed and compared with the images captured prior to the treatment. Of the total 13 lesions, four had disappeared, eight were reduced by $>50 \%$ and one was enlarged, indicating that the local control rate was $92.3 \%(12 / 13)$. Overall, two patients developed intraoperative pneumothorax and one experienced hemoptysis subsequent to the procedure. Following a median follow-up period of 31 months, no local recurrence was observed in 12 of the metastatic lesions. The mean survival time was 32.7 months and the median survival time was 31 months.
\end{abstract}

\section{Introduction}

Colorectal cancer (CRC) is the third most common malignancy in Western countries and is one of the leading causes of cancer-related mortality in China $(1,2)$. In total, approximately $10-25 \%$ of patients with CRC develop pulmonary metastases (3). As no effective chemotherapy regimen has been developed for the treatment of pulmonary metastases of colorectal origin, surgery is the only potentially curative

Correspondence to: Mr. Daqiang Sun, Department of Thoracic Surgery, Tianjin Chest Hospital, 93 Xi'an Road, Heping, Tianjin 300051, P.R. China

E-mail: sdqmd@163.com

*Contributed equally

Key words: colorectal cancer, pulmonary metastases, ${ }^{125}$ I seeds, computed tomography-guided treatment option. However, only $2-4 \%$ of pulmonary metastases can be treated surgically and others require external beam radiotherapy and chemotherapy (4). Increasing the therapeutic doses of traditional external beam radiotherapy is challenging due to the severe side-effects. Although three-dimensional conformal radiation therapy (3D-CRT) and stereotactic external beam radiotherapy can administer tumoricidal doses, the side-effect of lung tissue damage remains a problem (5).

Percutaneous computed tomography (CT)-guided radioactive ${ }^{125}$ I seed implantation (CTRISI) is a minimally invasive modality. This brachytherapy is less time consuming and less traumatic, compared with the aforementioned treatments, and the side-effect of radiation damage is minimal (6). Patients are also more likely to accept this therapy due the minimally invasive nature of the technique. CTRISI has been used for the treatment of non-small cell lung cancer (NSCLC) $(7,8)$. However, there have been few radioactive seed implantations for pulmonary metastases following resection of CRC and the efficiency of CTRISI has not been determined. The present study reports the preliminary results of six patients with pulmonary metastases following resection, who could not tolerate a surgical procedure and therefore, underwent CT-guided ${ }^{125}$ I brachytherapy.

\section{Materials and methods}

In total, six patients, three males and three females, with an ages range of 68-86 years (mean \pm standard deviation, $76.0 \pm 7.6$ years), with pulmonary metastases following colon cancer resection, were treated with percutaneous CTRISI at the Department of Thoracic Surgery, Second Hospital of Tianjin Medical University (Tianjin, China) between November 2002 and May 2010. Informed consent was obtained from the subjects and the present study was approved by the Ethics Committee of Tianjin Medical University. The patient characteristics are shown in Table I. Of the total 13 metastatic lesions, eight were located in the left lung and five in the right lung. In total, 10 were located in the lung and three were located beneath the hilum of the lung. The average diameter was $2.8 \pm 1.5 \mathrm{~cm}$ (range, $1-6 \mathrm{~cm}$ ) and the average volume was $29.5 \pm 29.4 \mathrm{~cm}^{3}$. A complication of right supraclavicular lymph node metastasis was observed in one case and subsequently received seed implantation.

The CT-guided brachytherapy procedure was carried out as previously described (9). Prior to the procedure, a treatment 


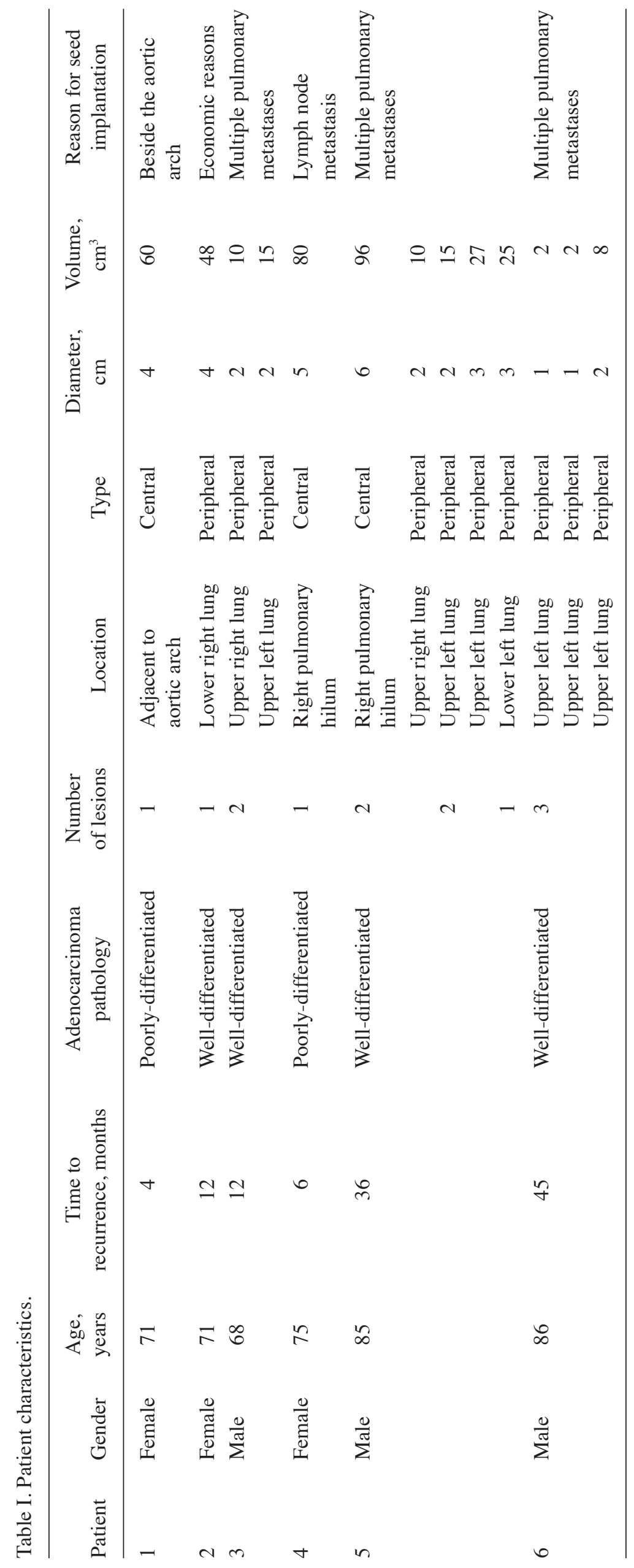




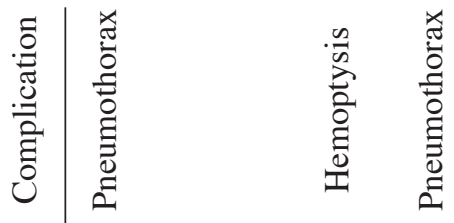

苞

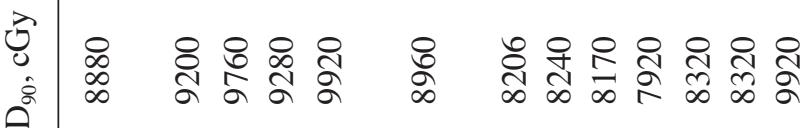

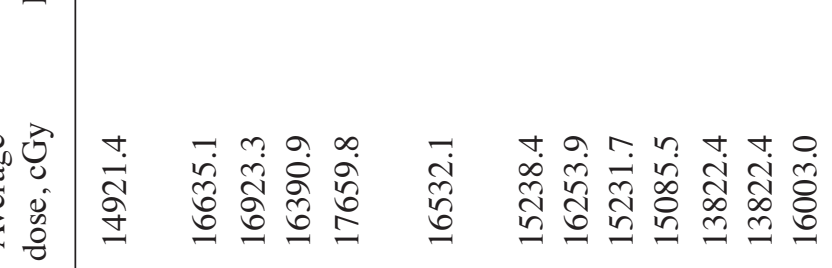

$m \ddot{n} \backsim$ ㅇํ

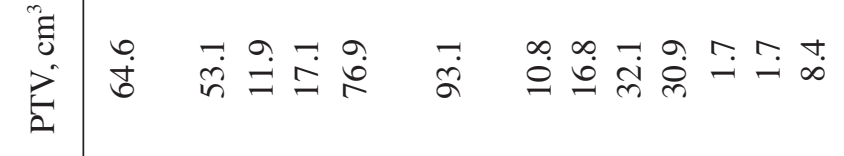

离苛売

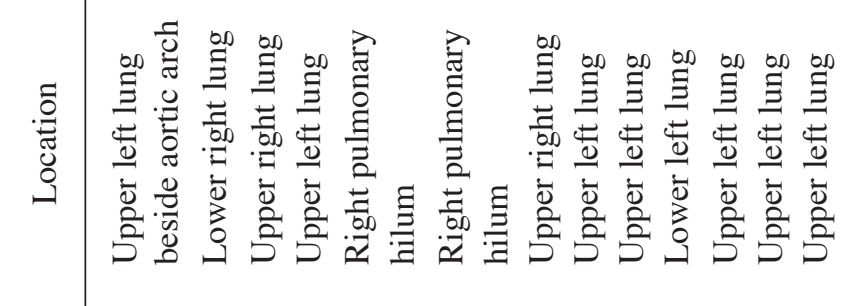

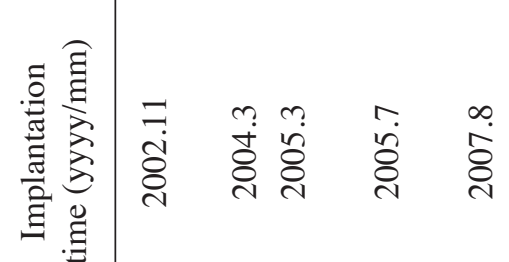

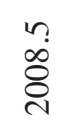


Table III. Follow-up and outcome of the disease.

\begin{tabular}{|c|c|c|c|c|c|}
\hline Patient & $\begin{array}{l}\text { Number of } \\
\text { lesions }\end{array}$ & Location & $\begin{array}{l}\text { Lesion status at } \\
\text { six-month follow-up }\end{array}$ & $\begin{array}{c}\text { Date of } \\
\text { death (month/year) }\end{array}$ & $\begin{array}{l}\text { Survival time, } \\
\text { months }\end{array}$ \\
\hline 1 & 1 & Adjacent to aortic arch & Decreased by $50 \%$ & $04 / 2005$ & 29 \\
\hline 2 & 1 & Lower right lung & Decreased by $50 \%$ & $04 / 2008$ & 49 \\
\hline 3 & 2 & $\begin{array}{l}\text { Upper right lung } \\
\text { Upper left lung }\end{array}$ & $\begin{array}{l}\text { Disappeared } \\
\text { Disappeared }\end{array}$ & 08/2009 & 53 \\
\hline 4 & 1 & Right pulmonary hilum & Enlarged & 03/2006 & 8 \\
\hline 5 & 2 & $\begin{array}{l}\text { Right pulmonary hilum } \\
\text { Upper right lung }\end{array}$ & $\begin{array}{l}\text { Decreased by } 50 \% \\
\text { Decreased by } 50 \%\end{array}$ & $05 / 2010$ & 33 \\
\hline & 2 & $\begin{array}{l}\text { Upper left lung } \\
\text { Upper left lung } \\
\text { Lower left lung }\end{array}$ & $\begin{array}{l}\text { Decreased by } 50 \% \\
\text { Decreased by } 50 \% \\
\text { Decreased by } 50 \%\end{array}$ & & 33 \\
\hline 6 & 3 & $\begin{array}{l}\text { Upper left lung } \\
\text { Upper left lung } \\
\text { Upper left lung }\end{array}$ & $\begin{array}{l}\text { Disappeared } \\
\text { Disappeared } \\
\text { Decreased by } 50 \%\end{array}$ & $05 / 2010$ & 24 \\
\hline
\end{tabular}

plan was prepared for each patient using a computerized treatment planning system (TPS; Prowess Panther, Prowess Inc., Concord, CA, USA) based on the CT images of the patients. The TPS generated a dose-volume histogram (DVH) and isodose curves of various percentages, and calculated the position (coordinates) of the brachytherapy applicator, dose and number of implanted seeds (Table II). Under local anesthesia, interstitial needles (Medical Device Technologies, Inc., Gainesville, FL, USA) were inserted into the tumor at $\sim 0.5 \mathrm{~cm}$ intervals. Each ${ }^{125}$ I seed was implanted within an average of $1 \mathrm{~cm}^{3}$ of the tumor. The average planning target volume (PTV) of the 13 metastatic lesions was $32.1 \pm 30.1 \mathrm{~cm}^{3}$, and the average number of implanted seeds was $28 \pm 14.4$ seeds. The average dose of the target area was $157.3 \pm 11.6 \mathrm{~Gy}$, with a median dose of $152.4 \mathrm{~Gy}$. The dose covered $90 \%$ of the volume $\left(\mathrm{D}_{90}\right), 88.4 \pm 7.3 \mathrm{~Gy}$, and the volume that received $>90 \%$ of the prescribed dose $\left(\mathrm{V}_{90}\right)$ was $31.5 \pm 29.5 \mathrm{~cm}^{3}$. Once the implant was completed, a CT scan was performed to verify the position and intensity of the ${ }^{125} \mathrm{I}$ seeds according to TPS. The six-month post-procedural follow-up was complemented by CT examination. The follow-up was completed in May 2010 (Table III).

\section{Results}

The brachytherapy catheters and ${ }^{125}$ I seeds were satisfactorily placed in all patients. Of the six patients, three developed pneumothorax during the procedure. These patients subsequently received chest-tube drainage as a curative treatment for the pneumothorax, and two to three days following this, the condition was resolved. Hemoptysis ( $\sim 20 \mathrm{ml})$ was observed in one patient; this ceased two days following the oral administration of carbazochrome salicylate ( $5 \mathrm{mg}$ three times a day, for three days).

Compared with the CT images captured prior to the procedure, the $\mathrm{CT}$ images obtained at the six-month follow-up revealed that four masses had been completely removed by the treatment and eight masses had been reduced in size by $>50 \%$. The CT images of one 86 -year-old male patient prior to and following the procedure are shown in Figs. 1-5. Overall, only one mass was enlarged, indicating that the local control rate was $92.3 \%$ (12/13). None of the patients developed radioactive pneumonia or reduction in peripheral-blood granulocytes. Following a median follow-up period of 31 months (32.7 \pm 16.6 months; range, 8-53 months), no local recurrence was observed for the 12 metastatic lesions. Of the two patients with poorly-differentiated adenocarcinoma, one suffered from pulmonary metastases, complicated by right supraclavicular lymph node metastasis six months following radical resection. One of these patients succumbed to the disease eight months following brachytherapy and the other succumbed 29 months following brachytherapy. The four patients with well-differentiated adenocarcinoma succumbed to the disease 49,53, 33 and 24 months following brachytherapy. The mean survival time was 32.7 months and median survival time was 31 months.

\section{Discussion}

The present study demonstrates that percutaneous CTRISI is a feasible and promising, minimally invasive modality for controlling the growth of pulmonary metastases following CRC resection, particularly in the 12 months following surgery. Although one patient experienced hemoptysis and three patients suffered pneumothorax, these side-effects could be controlled, indicating that CTRISI remains a safe treatment method in this patient population.

The target area may tolerate sustained, closer high-dose irradiation through the conformal implantation of seeds into the interior of the tumor, overcoming target volume motion, so that the local control rate can be elevated. Independent or separate entity radiotherapy studies have demonstrated that local control of the tumor body is likely to be markedly intensified following irradiation with a bioeffect dose of 90-100 Gy. Martínez-Monge et al used 


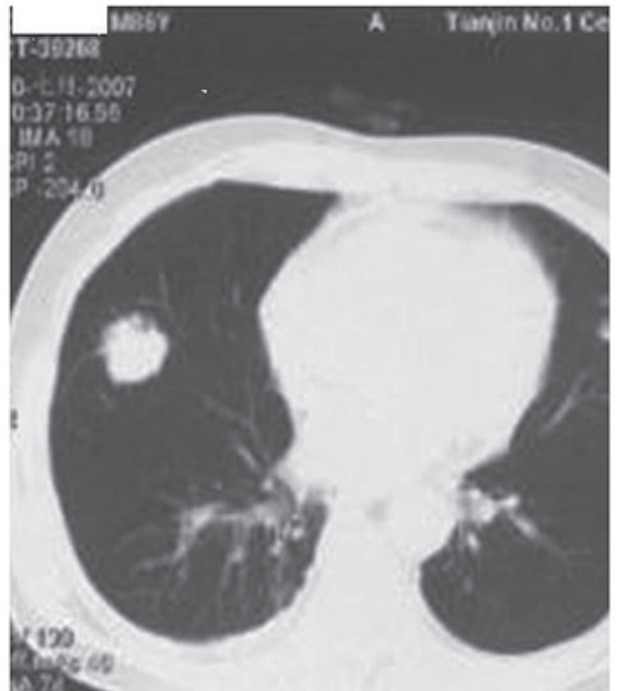

Figure 1. Male, 86 year-old patient 3 years following resection of colorectal cancer, revealing right lung metastases.

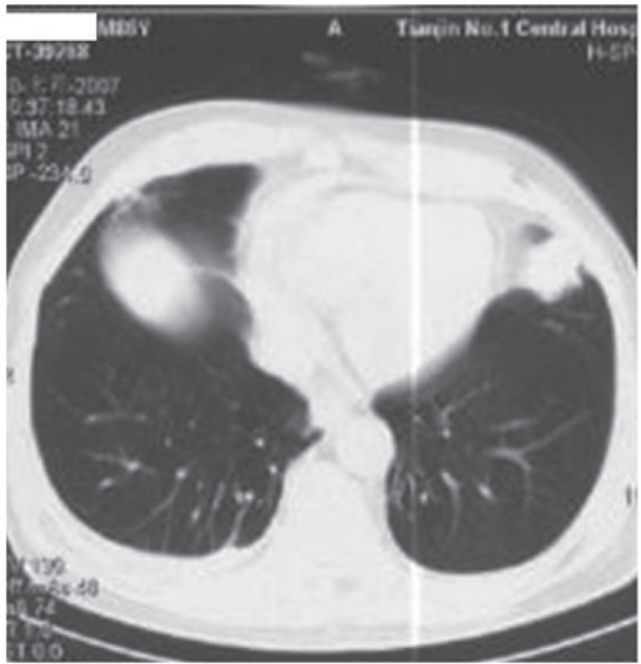

Figure 2. Male, 86 year-old patient 3 years following resection of colorectal cancer, revealing left lung metastases.

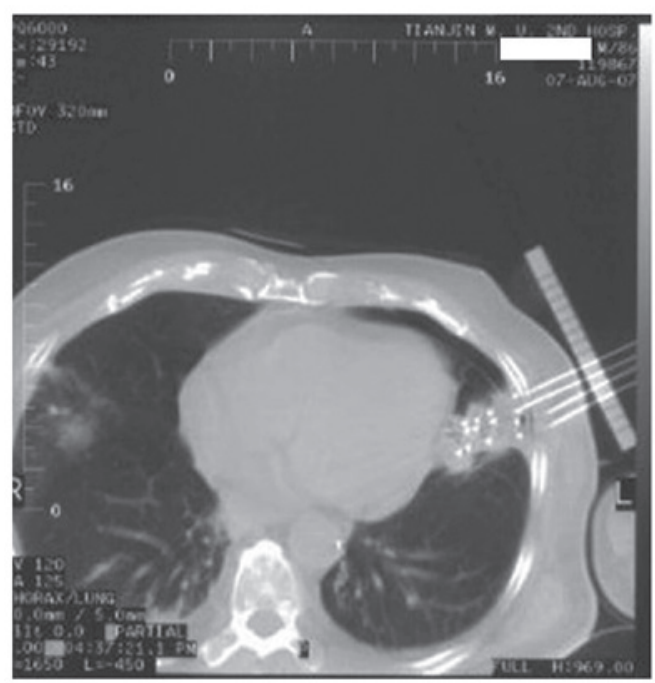

Figure 3. CT-guided ${ }^{125}$ I seed brachytherapy.

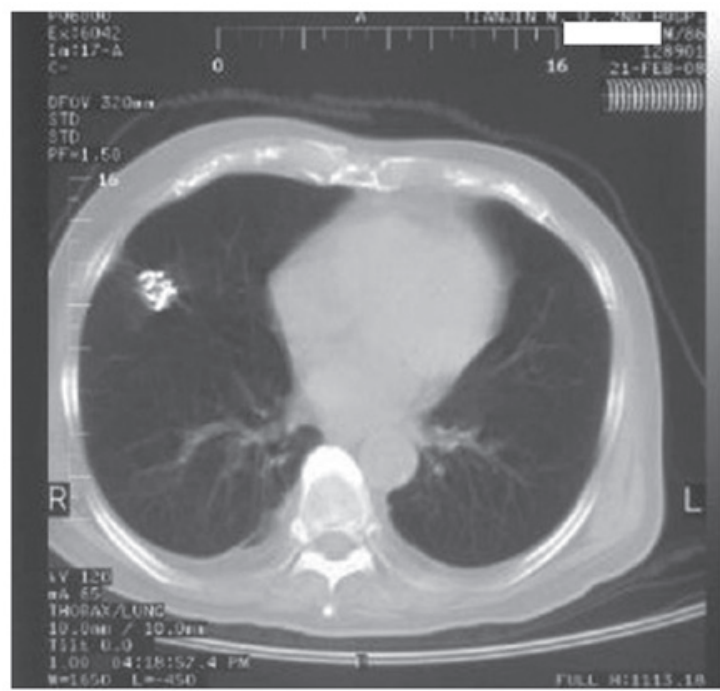

Figure 4 . Right pulmonary metastases was reduced by $>50 \%$ following ${ }^{125} \mathrm{I}$ brachytherapy for six months.

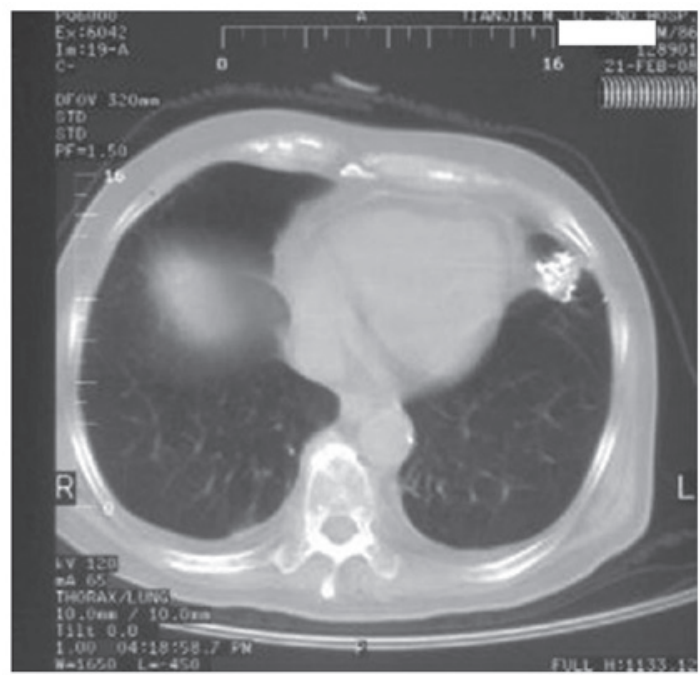

Figure 5. Left pulmonary metastases reduced by $>50 \%$ following ${ }^{125}$ I brachytherapy for six months.

CT-guided permanent brachytherapy to treat seven patients with early-stage T1NOM0 NSCLC. The median dose was 144 Gy. This study found that one patient developed a focal pneumonitis three months following the treatment, and no patients developed local or regional failure within a 13 month follow-up period (7). In the present study, the mean tolerance dose of PTV (gross tumor volume $+0.5 \mathrm{~cm}$ ) was $157.3 \mathrm{~Gy}$, with a median dose of $152.4 \mathrm{~Gy}$. The lesions were irradiated with a dose of approximately twice the PD and a local control rate of $92.3 \%$ was achieved, which is similar to the effective rate of $93.8 \%$ (10) for seed implantation for pulmonary metastases and $87 \%$ (11) for 3D conformal external beam radiotherapy, as previously reported in the literature, demonstrating good therapeutic effects. This may be associated with the high-dose irradiation of the small target area as well as with the sensitivity of well-differentiated adenocarcinoma to $\gamma$-ray radiation. 
The seeds can be accurately and evenly implanted into the target area under CT guidance. Patients with the target area located at the tumor center should undergo stereotactic puncture following contrast-enhanced CT scanning of blood vessels. The puncture needlepoint can be close to the heart and great vessels without injury to them. In the present study, $\mathrm{D}_{90} 88.4 \mathrm{~Gy}$ (>PD) revealed a uniform and reasonable dose distribution.

The ${ }^{125}$ I-ray seed ray decays in an exponential manner with distance, which can reduce damage to tissues around the target area. The occurrence rate of radioactive pneumonia has been reported to be $44 \%$ (12) when the average therapeutic dose of the $3 \mathrm{D}$ conformal radiotherapy is $60 \mathrm{~Gy}$. In the present study, no radioactive pneumonia was observed at PD 80 Gy, suggesting that seed implantation causes less damage as a result of radioactivity than conventional radiotherapy. Puncture-induced pneumothorax and hemoptysis can be observed on CT imaging and can be treated using conventional methods.

In conclusion, CTRISI is a safe and minimally invasive treatment modality for metastases from CRC that may aid in prolonging the survival rate in patients who cannot undergo pulmonary resection for metastases. While these results are promising, future studies including an increased number of cases, are required to gain further information with regard to CTRISI for the treatment of pulmonary metastases following CRC resection.

\section{References}

1. Ferlay J, Soerjomataram I, Dikshit R, et al: Cancer incidence and mortality worldwide: sources, methods and major patterns in GLOBOCAN 2012. Int J Cancer. Sep 13, 2014 (Epub ahead of print).
2. Talton BM, Constable WC and Kersh CR: Curative radiotherapy in non-small cell carcinoma of the lung. Int J Radiat Oncol Biol Phys 19: 15-21, 1990.

3. Rama N, Monteiro A, Bernardo JE, Eugénio L and Antunes MJ: Lung metastases from colorectal cancer: surgical resection and prognostic factors. Eur J Cardiothoracic Surg 35: 444-449, 2009.

4. Talton BM, Constable WC and Kersh CR: Curative radiotherapy in non-small cell carcinoma of the lung. Int J Radiat Oncol Biol Phys 19: 15-21, 1990.

5. Belderbos JS, Heemsbergen WD, De Jaeger K, Baas P and Lebesque JV: Final results of a Phase I/II dose escalation trial in non-small-cell lung cancer using three-dimensional conformal radiotherapy. Int J Radiat Oncol Biol Phys 66: 126-134, 2006.

6. Cha CM, Potters L, Ashley R, et al: Isotope selection for patients undergoing prostate brachytherapy. Int J Radiat Oncol Biol Phys 45: 391-395, 1999.

7. Martínez-Monge R, Pagola M, Vivas I and López-Picazo JM: CT-guided permanent brachytherapy for patients with medically inoperable early-stage non-small cell lung cancer (NSCLC). Lung Cancer 61: 209-213, 2008.

8. Zhang FJ, Li CX, Wu PH, et al: CT guided radioactive ${ }^{125} \mathrm{I}$ seed implantation in treating localized advanced pulmonary carcinoma. Zhonghua Yi Xue Za Zhi 87: 3272-3275, 2007 (In Chinese).

9. Martínez-Monge R, Garrán C, Vivas I and López-Picazo JM: Percutaneous CT-guided 103Pd implantation for the medically inoperable patient with T1N0M0 non-small cell lung cancer: a case report. Brachytherapy 3: 179-181, 2004.

10. Bradley J, Graham MV, Winter K, et al: Toxicity and outcome results of RTOG 9311: a phase I-II dose-escalation study using three-dimensional conformal radiotherapy in patients with inoperable non-small-cell lung carcinoma. Int J Radiat Oncol Biol Phys 61: 318-328, 2005.

11. Timmerman R, McGarry R, Yiannoutsos C, et al: Excessive toxicity when treating central tumors in a phase II study of stereotactic body radiation therapy for medically inoperable early-stage lung cancer. J Clin Oncol 24: 4833-4839, 2006.

12. Baumann P, Nyman J, Hoyer M, et al: Outcome in a prospective phase II trial of medically inoperable stage I non-small cell lung cancer patients treated with stereotactic body radiotherapy. J Clin Oncol 27: 3290-3296, 2009. 